\title{
Pteknokultura
}

\#Corominas Botana, D. (2015). Nunca tan rápido ni tan grande. Revista Teknokultura, Vol. 12(1), 177-186.

Recibido: 17-03-2015

Aceptado: 23-03-2015
Link Open peer review:

http://revistas.ucm.es/index.php/TEKN/pages/view/opr-272

\section{Nunca tan rápido ni tan grande}

\author{
Never as fast or as big as this \\ David Corominas Botana \\ BMC Strategic Innovation \\ corominas.davidegmail.com
}

\section{Resumen}

El texto se asoma a varias claves comunicacionales y estratégicas del éxito de Podemos como propuesta retadora al establishment español: éxito en las elecciones europeas y en intención de voto demoscópico posterior. Se reconoce la capacidad de leer el pulso social, de capturar los insights fundamentales de los ciudadanos españoles, y el acierto de convertidos en armas electorales toda vez que en argamasa de una organización política que no ha hecho más que aumentar su dimensión, mes a mes. El argumento se construye mediante una breve aproximación a tres casos de éxito electoral de opciones políticas contrarias al poder hegemónico en sus países: Syriza, Grecia 2015, M5S, Italia 2013 y Obama, EE.UU. 2008. Se observan diferencias y similitudes, pero, sobre todo, se constata que lo más identificativo de Podemos es la combinación entre la velocidad de crecimiento y la dimensión de su apoyo. 


\section{Palabras Clave}

Podemos, Syriza, M5S, Obama, Beppe Grillo, insight social, discurso político, hegemonía, establishment.

\section{Abstract}

This paper sets out several communication and strategic features of Podemos' success as a challenging proposition to the Spanish establishment: success in the European elections and in the opinion polls to gauge voting intention. It looks at the capacity of Podemos to put its finger on society's pulse, to capture the deepest insights of Spanish citizens, and to convert triumphantly the masses into electoral arms while cementing a political organization, which has quite simply kept expanding month after month. Its argument is based on an overview of three cases of electoral success involving political choices that go against the hegemonic powers in their own countries: Syriza in Greece 2015, M5S in Italy 2013 and Obama in USA 2008. It discusses differences and similarities, but above all it will note the most distinctive element of Podemos: a combination of speed of its rise and the extent of its support

\section{KEYWORDS}

Podemos, Syriza, M5S, Obama, Beppe Grillo, social insight, political discourse, hegemony, establishment.

\section{SuMARIO}

Syriza

Obama 2008

M5S (Movimento 5 Stelle)

\section{SUMmary}

Syriza

Obama 2008

M5S (Movimento 5 Stelle) 
Mucho se ha escrito sobre Podemos, sobre su corta y deslumbrante historia, de su éxito en las elecciones al parlamento europeo en 2014 y del rosario demoscópico que no deja de mostrar horizontes plagados de buenos resultados. Mucho se ha dicho ya sobre un partido que cabalga sobre expectativas envidiadas por todos.

En mi caso, la aproximación que haré en estas líneas tiene la peculiaridad de escribirse a $12.000 \mathrm{~km}$ de España, y de que su autor ha vivido durante todo el año 2014 a orillas del río de la Plata. Es, por tanto, una reflexión en la distancia geográfica que no emocional. Quiero subrayar lo de emocional porque, más allá de contenidos programáticos (agenda de economía feminista, propuestas de Navarro y Torres, etc.) y devenires orgánicos (encuentro de Vista Alegre; primarías regionales, etc.) el fenómeno Podemos, para cualquiera que se dedique a la estrategia y la comunicación de manera profesional, tiene que afectar en las emociones, no se recuerda en la historia política occidental democrática de las últimas 5 décadas nada similar a lo que han vivido los españoles justo en el año en que la selección de fútbol comenzaba el mundial como campeona y se volvía a casa en la primera fase.

En menos de 12 meses un modesto ejercicio electoral enfocado a levantar una bandera contra el "austericidio" manufacturado por la troika (poco más esperaban los que se reunieron en el Teatro de Alberto San Juan en enero de 2014), está llamando a las puertas del parlamento con altas expectativas de ocupar muchos asientos. Aquello no era más que un grito de indignación queriendo ser papeleta electoral. Y trasmutó en una patada al tablero político, según indica el CIS.

Me gustaría utilizar tres ejemplos foráneos para apuntar, por aproximación, como si de un zahorí se tratara, alguna de las claves del auge del joven partido español. No se busca un riguroso análisis comparativo sino más bien iluminar ciertas semejanzas y subrayar alguna diferencia con otras opciones electorales que sorprendieron a los expertos e incomodaron (e incomodan) a los conservadores y tradicionalistas.

He decidido elegir tres opciones electorales exitosas, recientes e interesantes de la política internacional; tres hitos con suficiente cobertura mediática, y por tanto conocidos por todos, para asomarme al "fenómeno" Podemos: Syriza, Obama 2008 y el M5S italiano. Diré que ni Syriza, que llevaba varias elecciones a cuestas, ni Obama, candidato sorpresa a la cabeza de 
una maquinaria política convencional, ni el M5S, artilugio de Beppo Grillo, han disfrutado de la aceleración en su crecimiento orgánico o de la capacidad performativa de su verbo, de mostrada por el partido español heredero lejano del 15M.

\section{Syriza}

Hoy se presentan, Syriza y Podemos, como organizaciones hermanas. La suerte del partido español está ligada a la pericia del gobierno de Alexis Tsipras en gambetear las barreras que ya le están poniendo Merkel y sus aliados europeos, entre los que actúan conspicuamente Rajoy y su gabinete. Hoy parece más importante mirar a Atenas que a Caracas para calibrar el techo de Podemos.

Con todo, no debemos olvidar que Syriza tiene una etiología bien diferente a la del partido de Pablo Iglesias. En 2004 nació como gran coalición de hasta 13 partidos dispares, situados entre el poderoso PASOK y el incombustible KKE (comunistas prosoviéticos). Syriza es un "Frente Amplio" à la helénica, reivindicándose de izquierda y aglutinando un magma social ideológicamente marcado por varias guerras civiles, dictaduras militares y corruptelas infinitas. El partido de Tsipras nunca renunció a sus referentes históricos múltiples y a la tradición izquierdista. Fue una coalición de crecimiento lento, llena de batallas internas entre la sopa de siglas que lo configuraban, y que finalmente se disolvieron en un solo partido en 2013. Cuando hace unos meses llegaron al poder, con amplia mayoría relativa, disponían de experiencia en el ejercicio de gobiernos locales, regionales y un par de años de oposición parlamentaria. Su líder rompe con una tradición casi hereditaria del poder en Grecia. Pero ojo, los cuadros importantes de Syriza son militantes con mucha experiencia de gobierno. Algunos incluso provienen de la alta jerarquía del PASOK. No se trataría por tanto de una activación de la indignación contra un "régimen" falto de representatividad sino de una toma de posición ideológica enfrentada a un bipartidismo lacayo y ventajista del status quo dictado por la troika, defensora de los intereses financieros centroeuropeos.

Las manifestaciones iniciadas en 2008 por la muerte del joven anarquista Alexandros Grigorópulos desencadenaron una movilización a travesada por el descontento social vehiculado por organizaciones libertarias y anticapitalistas. El descontento pronto encontró en el frente de partidos de izquierda con cierta visibilidad electoral, un referente. Además, la protesta nunca pudo ser neutralizada por un partido socialista partícipe en el saqueo 
económico del país y se fue aglutinado en la opción que con más contundencia rechazaba las directrices europeas que estaban multiplicando la austeridad: Syriza. En un país pequeño, con poca población y con un alto grado de cohesión nacional, el discurso de Syriza caló rápidamente en la población urbana, dejando el campo para recolección del voto conservador.

Conviene señalar que en términos de posicionamiento y estrategia, Syriza no ha cambiado los ejes del tablero político griego, allí, por ejemplo, no se cumple la idea de que los significantes izquierda y derecha ya no dan cuenta de las tensiones, insights y soluciones del conflicto social y económico. En Atenas nunca desapareció la prensa marxista de los quioscos, nunca se renunció a la iconografía y liturgia de herencia sociocomunista. La apuesta de Syriza ha sido la reivindicación de un frente antiausteridad, anticorrupción, proestatalista desde posiciones izquierdistas. Su cúpula dirigente, frente a la de Podemos, ha tenido poco vínculo explícito o directo con los gobiernos populistas latinoamericanos.

Los líderes más visibles de Podemos han militado o transitado por organizaciones de izquierda o extrema izquierda, pero han renunciado a explicitar ese bagaje por entender que no era condición necesaria. Tampoco han gavillado organizaciones preexistentes, salvo IA, y, sin negar dobles militancias, han prohibido expresamente el disfrute de cargos a militantes de otros partidos desde el inicio. El trabajo de base no ha venido nucleado por formaciones previas sino en correlatos "quincemistas" de asamblearismo territorial o temático. Por cierto, cuando Pablo Iglesias se inició en el liderazgo de Podemos, ya sabía inglés, Tsipras lo ha aprendido a las apuradas en los últimos años.

\section{Obama 2008}

En el caso del actual presidente estadounidense, inicialmente candidato de uno de los dos partidos del establishment de esa república federal, uno podría pensar que el parecido con Podemos es más que remoto. Es cierto. Sin embargo, hay tres características que merece la pena subrayar porque formaron parte del éxito de la candidatura de Barak Obama, tanto en las primarias que lo ubicaron como aspirante a la Casa Blanca como en la presidenciales en las que venció al candidato republicano John Mcain, y dan alguna pista sobre el éxito de Podemos.

Como preámbulo, no es menor recordar que la posición del abogado de Illinois era marcadamente outsider en el aparato del Partido Demócrata, y su agenda programática poco convencional, igual que su propia biografía. 
El primer gran acierto de Obama fue contar con el apoyo del equipo de campaña de Howard Dean, un candidato derrotado en las primarias demócratas de 2004. Un político, también él, con un discurso marcadamente progresista en el contexto de EE.UU pero sobre todo con una visión del ecosistema digital online que marcó un antes y un después en el contexto electoral yanqui. Supo leer avant la lettre la centralidad de internet para la movilización social del siglo XXI. Su equipo, tras la derrota, saltó al pequeño cuartel general del afroamericano y se pasó años construyendo la arquitectura participativa en las redes. La verdad es que pocas veces en la historia electoral norteamericana un candidato ha sabido movilizar y coordinar movimientos sociales de base a su favor sin activar clientelismos disciplinados y perversos. El malestar ante los años de la administración Bush era grande, EE.UU vivió en esa época una auténtica ola de acción colectiva antigubernamental apenas retratada por los medios. La paradoja es que pese a ser mucho más grande que las movilizaciones contra la guerra del Vietnam, las capacidad de alterar el curso de los acontecimientos fue mucho más magra (pensemos en la guerra de Irak). En este contexto de descontento activo, los estrategas del futuro presidente supieron leer los insights sociales de época en su país: participación, indignación, autonomía de acción, deseo de cambio, y transformarlos en iniciativa política con objetivos electorales. El ejemplo paradigmático son las propuestas gráficas y audiovisuales que los activistas generaban motu proprio y que fueron utilizadas extensivamente por la maquinaria electoral oficial. En eso el parecido con Podemos es sorprendente, aunque en el caso español, el partido de Iglesias cabalgo con sumo acierto sobre las redes telemáticas y dinámicas preexistentes, consolidadas a partir del 15M.

El segundo acierto de Obama fue redefinir, desde parámetros impensables, la importante batalla de la financiación, corazón de toda campaña electoral en EE.UU. El candidato y su equipo activaron el llamado "muchos pocos" frente a la opción clásica de "pocos muchos". El candidato era un outsider, no disponía de fortuna personal capaz de sostener los infaustos costes de unas elecciones presidenciales, no generaba demasiada confianza al inicio (casi todas las grandes fortunas donan a ambos contrincantes de una u otra manera) y necesitaba liquidez inmediata. El Partido Demócrata puso en marcha todo un entramando de micro donaciones constantes, que todavía sigue activo para movilizaciones puntuales. Logró de esta manera alcanzar dos objetivos: el dinero que necesitaba, y que cualquier ciudadano no importa su condición económica, se sintiera partícipe de un movimiento de cambio que no paraba de crecer. El uso de internet fue brillante en esta área. Antaño, estas donaciones personales existían pero se realizaban casi puerta a puerta, desde 2008 el click activismo también incluía la click financiación. En este sentido, Podemos también ha marcado un camino ejemplarizante 
toda vez que eficaz. Las campañas y actividades diversas del partido, se están financiando vía microdonaciones, microcréditos y crowdfunding, con una transparencia inusitada en España (a pesar de los titulares de la prensa conservadora, es decir casi toda).

Finalmente, conviene dejar un apunte breve sobre los discursos de Barak Obama durante la campaña de 2008. Bajo un argumentario de cambio, reivindicando a las clases populares frente al abuso de la élite corporativa, y apelando a la unidad nacional, a la patria y sus relatos emocionales historicistas (que por primera vez incluían a grupos étnicos siempre olvidados), estos discursos lograron disparar unos niveles de emotividad enorme. Si bien se dirigían "a la gente decente de EE.UU", hicieron llorar a medio mundo. La epitome de su emocionalidad discursiva puede situarse en el speech de las primarias de New Hampshire, donde utilizando frases que le lanzó una viejita al salir de un servicio religioso, construyó su locución " fire up, ready to go" y donde, además, apareció el archifamoso "yes we can" (por cierto, la frase es la traducción inglesa de un grito de lucha de campesinos latinos de Arizona allá por los 70 "¡sí, se puede!”). En este sentido, sorprende leer, en España, críticas rabiosas que se lanzan contra los discursos de Podemos por bascular en lo emocional... por suerte, ninguno de esos dardos iracundos está firmado por estrategas electorales de los partidos mayoritarios, ni por sus redactores de discursos. Estos saben que el contexto del texto de un discurso de gran auditorio pide emocionalidad, ese es su objetivo, y su termómetro de éxito. Cuando la política está en manos de, o mejor dicho en el verbo de, las Salgado, los Solbes, las Cospedal, los Montoro o los Rubalcaba , la emoción quedaba recluida en las canchas de fútbol y no en todas. Podemos, como Obama y su equipo, sabe que sin pasión no hay activismo político, y sin activismo, la política se hace en despachos y pasillos exclusivamente. No es un canto de sirenas, son las reglas retóricas del juego.

\section{M5S (Movimento 5 Stelle)}

La podredumbre de las instituciones italianas llegó a su culmen con la caída de la todopoderosa Democrazia Cristiana al inicio de los 90. Desde entonces la clase política de Italia ha ido acumulando descrédito y desprecio, a ritmo lento pero firme, en España todo ha sido más rápido, parece. En 2009, un cómico de enorme éxito por sus diatribas contra el poder, al mejor estilo Dariofoista, da el paso y transforma el mayor blog de lengua italiana en un partido. Su organización se construye como antítesis de los partidos históricos, incluidos los de extrema izquierda asamblearia, y cuyo principal eje discursivo es el malestar ciudadano 
con la clase dirigente, con sus abusos y corruptelas. En 2013, el Movimento 5 Stelle (Cinco por: agua pública, transporte, conectividad, desarrollo y medio ambiente), con un claro discurso antiestablishment y anticorrupción, se convierte en el partido más votado del país de Gramsci. No formó gobierno por su rechazo a coaligarse con alguna opción de la vieja política. Los legisladores electos del partido de Grillo son por lo general bisoños en la política institucional, pero muy participativos en movilizaciones sociales, profesionales urbanos y con estudios, muy descontentos sino indignados con las opciones tradicionales en juego ¿les suena?

La gran diferencia con Podemos, en principio, la encontramos en los orígenes y las formas de gestión de la organización. Si bien M5S se declara, y de hecho funciona, como un movimiento electoral crecido al calor de listas cívicas, ${ }^{1}$ cuyo origen y máxima referencia fue y es el cómico en cuestión, Beppo Grillo (así lo indican los puntos iniciales de sus estatutos), también se autodefine como una "no-asociación" (sic) dispuesta a desaparecer en el momento en que sus demandas comiencen a cumplirse. Demandas alejadas de la izquierda tradicional en tanto que son poco estatalistas. Sí, en cambio, defienden, y de manera rabiosa un programa medioambiental radical, a la vez que mecanismos de transparencia de mercado, pues reivindican la economía de libre mercado bajo estrictas regulaciones que defiendan a los pequeños emprésitos frente a los grandes conglomerados, en esto coincide poco con Podemos. Desde luego sus referentes no los encontraremos en lo movimientos populares de Latinoamérica ni en la tradición neomarxista de Grecia. Tampoco en la muy autorrefencial política norteamericana. Pero sí en una tradición cívica italiana que hunde sus raíces en la Baja Edad Media.

Diremos, por no extendernos, que uno tiene la impresión de estar con Grillo ante un tribuno de la plebe, un Graco, revisitado que hace frente a los optimates de todo el espectro parlamentario, desde neocomunistas a posfascistas. $\mathrm{Y}$ si bien el discurso de $5 \mathrm{~S}$ es "antisistema" movilizador y exitoso, la omnipresencia de su fundador y su alter ego en la sombra Gianroberto Casaleggio, empresario y consultor de estrategias online cofundador del

\footnotetext{
${ }^{1}$ El movimiento cívico italiano había tenido hasta la fecha expresiones partidarias con marcadas matices moralizantes y de mucho valor simbólico pero con clara incapacidad de romper un techo electoral ajustado: Antonio di Pietro, L'Italia dei Valori, etc. Asimismo, en Italia ha desaparecido casi por completo el referente socialdemócrata. La crisis económica no ha tenido efectos sociales tan devastadores como en Grecia y en España. Grillo no es el producto de ninguna lucha contra la austeridad. Podemos y Syriza sí lo son. Por ello el M5S responde a una lógica bien distinta: una lógica de moralización de la vida pública, de condena de toda la clase política sin paliativo ni excepción
} 
partido, hace que su modelo se parezca más, efectivamente, al de un tribuno digital con un programa básico.

Sorprende también, y en esto se distancia enormemente del joven partido español, su negativa a participar en shows televisivos. De hecho, algún cargo electo ha sido expulsado por incumplir esta norma. Su fuerza está en su ágil y movilizadora organización en red, virtual y real. Y de nuevo, en haber sabido entender el malestar social y haber acertado en convertirlo en un proyecto político de abordaje de las instituciones. Proyecto, en fin, atractivo para muchos ciudadanos cansados de una élite política y empresarial que viene esquilmando la economía del país bajo la atenta mirada de la Cosa Nostra.

En definitiva, a través de estos ejemplos expuestos, vemos que Podemos no ha inventado la rueda en lo que se refiere a dar expresión política a la indignación social inmersa en ciclos de intensa movilización. Tanto en EE.UU, como en Italia o Grecia, ese fue el denominador común para el nacimiento de opciones por fuera del establishment. Además, el uso certero de las redes telemáticas ya aparece en otros movimientos con raíces cívico-populares. Aunque es cierto que Podemos ha desarrollado algunos espacios asamblearios online sin parangón. Incluso el recurso estratégico de la emotividad fue ampliamente practicado por Obama o Grilllo, junto con el desarrollo de eslóganes de amplia aceptación y uso. Tampoco, aquí Podemos actúa de manera solipsista, los ecos de otros procesos políticos, incluso no reivindicados, resuenan en los círculos.

Sin embargo, y sin adentrarnos en lo relativo al contenido programático de Podemos, es de rigor reconocer la eficacia de sus pasos estratégicos en el proceso de construcción de partido y en el desarrollo de su acción comunicativa. A mi entender, el gran logro inicial de los de Pablo Iglesias ha sido convertir la indignación en esperanza de cambio (no juzgo aquí la capacidad de llevar a buen puerto ese cambio, solo subrayo el enorme acierto en dibujar la hoja de ruta que los españoles parecen querer votar); lo ha hecho a través del difícil ejercicio de convertir los insights sociales en propuestas político-electorales. A ello le ha sumado una organización que se ofrece (y se construye) como diferencialmente mejor a ojos de muchos votantes y militantes que ilusionados se van sumando al partido. Con todo, el coraje de Podemos es hacerlo en un contexto donde la hegemonía ideológica (y económica) apenas deja resquicios para una alternativa y mucho menos para un órdago de estas características.

Con los ejemplos esbozados, se muestran 3 casos donde, en circunstancias no equiparables pero no tan alejadas, se han vivido enmiendas a la totalidad del sistema hegemónico, sin salirse del juego democrático, como propone Podemos. Asimismo se indican cuáles fueron las claves de sus buenos resultados en las urnas. En España y para Podemos, lo que nos queda por 
comprobar es si su acierto en la construcción de nuevos marcos (discursivos) político institucionales se traduce en victorias electorales y si estas nos depararían auténticos procesos de cambio.

Aunque como dice un viejo amigo: "mira, hasta aquí un éxito". 